\title{
Wood hardening by methoxymethyl melamine
}

\section{F. Miroy, P. Eymard, A. Pizzi}

ENSTIB, Université de Nancy 1, Epinal, France

Subject Methoxymethyl melamine reacts covalently with hydroxy groups in wood forming a hardened network.

Materials and methods Liquid hexamethoxymethyl melamine (Maprenal MP 900, Hoechst) was used to impregnate samples of European beech sapwood of dimensions $100 \times 50 \times 30 \mathrm{~mm}$ by a vacuum/pressure process (vacuum $=30$ minutes at $25^{\circ} \mathrm{C}$; Pressure $=3.5$ bar for 30 minutes). After impregnation the samples were put in an oven at a temperture of $150^{\circ} \mathrm{C}$, with or without a metallic mould surrounding the sample, for a period of 8 or 16 hours. The samples were then tested for Brinell hardness and for volume increase for 2 hours, 24 hours and 5 days in water.

Results The results in Table 1 show that hexamethoxymethyl melamine, which is not capable of reacting with itself, hardens by reaction with the constituents of wood by giving wood of considerably improved Brinell hardness and of lower volumetric variation in water. Hexamethoxymethyl melamine is a chemical which is reacted with polyols to yield exterior car coatings, and is thus capable of reacting with hydroxygroups in wood as it would react with hydroxygroups of a polyol. Introduction of a separate polyol jointly with hexamethoxymethyl melamine does not improve the results already shown in Table 1 , confirming that wood acts as the polyol in the reaction. The use of a mould, by limiting resin flow out of the wood during curing improves
Table 1. Physical properties of beech sapwood after reaction with methoxymethyl melamine

\begin{tabular}{llllll}
\hline & $\begin{array}{l}\text { Brinell } \\
\text { hardness }\end{array}$ & \multicolumn{2}{l}{$\begin{array}{l}\text { Volumetric increase (\%) } \\
\text { in water }\end{array}$} \\
\cline { 5 - 6 } & & & $2 \mathrm{~h}$ & $24 \mathrm{~h}$ & $5 \mathrm{~d}$ \\
\cline { 5 - 6 } \cline { 5 - 6 } & & & 3.5 & 9.1 & 14.4 \\
treated and hardened & 5.44 & & 2.4 & 5.3 & 6.9 \\
treated and hardened in mould & 9.44 & & 2.2 & 6.4 & 6.9 \\
\hline
\end{tabular}

the Brinell hardness, due to the higher residual resin content in the wood. The volumetric variations and dimensional stability improve ments obtained are however comparable with and without mould, indicating that dimensional stability of the treated wood appears to be relatively independent of resin load in the load range $40 \%$ to $80 \%$ of resin on dry wood, contrary to the Brinell hardness which appears to be very dependent from resin load. The long time of curing needed, as well as the high curing temperature, can be considerably lowered by the addition of catalytic amounts of $p$-toluenesulphonic acid to yieid hardening rates and temperatures closer to industrial interest. Use of the mould is also likely to be eliminated by the use of the same catalyst. Hexamethoxymethyl melamine is a transparent, colourless finish and does not burn. 